\title{
Coverage and effectiveness of hypertension screening in different altitudes of Tibet autonomous region
}

Ci Song ${ }^{1,2}$, Virasakdi Chongsuvivatwong ${ }^{2}$, Suolang Wangdui ${ }^{3}$, Danzeng Mima ${ }^{4}$, Cuoji Zhuoma ${ }^{5}$, D. Ji ${ }^{1}$, Ouzhu Luobu ${ }^{1}$ and Hutcha Sriplung ${ }^{2^{*}}$ (D)

\begin{abstract}
Background: Tibet is an autonomous region in China located around an average altitude of $4500 \mathrm{~m}$ above sea level. Since 2012 the local government of Tibet has been providing free physical examinations, including screening for hypertension. However, the coverage and effectiveness of this free program have not been uncovered. This study aims to assess the coverage and effectiveness of hypertension screening and management program in 3 altitude levels of Tibet, and also the determinants of the success of the screening program.

Methods: A stratified cluster survey was conducted among 1636 residents aged 18 years or over in three different altitude areas in Tibet. We adjusted for age and sex based on national census data and used weighted logistic regression models to find factors associated with hypertension screening.

Results: The coverage of the hypertension screening program evaluated by participation rate in the previous screening was $94.9 \%$, while $24.7 \%$ (95\% Cl: $22.1-27.3 \%$ ) of them were diagnosed with hypertension. Females and alcohol drinkers were more likely to be screened. Among those diagnosed with hypertension, $28.7 \%$ had it under control. High altitude areas had a high proportion of controlled hypertension. The overall rate of controlled hypertension in high, moderate and low altitude areas was 35.1\% (95\% Cl: 24.8-45.3\%), 32.7\% (95\% Cl: 22.2-43.2\%) and $23.7 \%$ (95\% Cl: 14.7-32.6\%), respectively. Younger aged persons were more likely to have better control of their hypertension.

Conclusions: The coverage of hypertension screening in Tibet was high, especially in the low altitude areas. However, the effectiveness of hypertension control was low, indicating a need to implement the treatment adherence routines into the current screening interventions.
\end{abstract}

Keywords: Hypertension screening, Program coverage, Altitude, Tibet

\footnotetext{
* Correspondence: hutch.s@psu.ac.th

${ }^{2}$ Epidemiology Unit, Faculty of Medicine, Prince of Songkla University, Hat Yai, Songkhla 90110, Thailand

Full list of author information is available at the end of the article
}

C C The Author(s). 2021 Open Access This article is licensed under a Creative Commons Attribution 4.0 International License, which permits use, sharing, adaptation, distribution and reproduction in any medium or format, as long as you give appropriate credit to the original author(s) and the source, provide a link to the Creative Commons licence, and indicate if changes were made. The images or other third party material in this article are included in the article's Creative Commons licence, unless indicated otherwise in a credit line to the material. If material is not included in the article's Creative Commons licence and your intended use is not permitted by statutory regulation or exceeds the permitted use, you will need to obtain permission directly from the copyright holder. To view a copy of this licence, visit http://creativecommons.org/licenses/by/4.0/. The Creative Commons Public Domain Dedication waiver (http://creativecommons.org/publicdomain/zero/1.0/) applies to the data made available in this article, unless otherwise stated in a credit line to the data. 


\section{Background}

Hypertension (HT) is a significant health problem affecting $31.1 \%$ of the global population and leads to morbidity and mortality worldwide [1]. High blood pressure (BP) is a prevalent and essential promoter of vascular damage resulting in cardiovascular diseases (CVD). Many risk factors for hypertension are behavioral and modifiable. The control of blood pressure is crucial in the prevention of CVD $[2,3]$.

China initiated the community-based prevention of CVD project in 1969 as a comprehensive intervention program that focused on the prevention and treatment of hypertension. Since the 1970s, similar centers and pilot programs expanded to various provinces and autonomous regions of China [4]. According to the results of past national hypertension screening surveys, the prevalence of hypertension among the general population aged 18 years or older in China increased from $7.7 \%$ in 1979 to $18.0 \%$ in 2002 and $38.0 \%$ in 2010 [5-7] In 2009 , the fourth new medical reform policies brought community-based prevention of hypertension and diabetes into the agenda of national public health services $[8,9]$. For several decades, the intervention program has extended from the treatment of individuals with hypertension to large-scale management in communities and the prevention of comorbidities [4].

Tibet is an autonomous region in the southwest of China located around an average altitude of $4500 \mathrm{~m}$ above sea level [10]. In 2015 the estimated population of Tibet was 3.23 million, with ethnic Tibetans comprising $90 \%$ of the whole community [11]. In 2015, the regional's disease surveillances showed three major diseases in Tibet that were chronic diseases, infectious diseases and maternal nutritional deficiency diseases and top five causes of death that were cerebrovascular diseases, respiratory diseases, heart diseases, digestive system diseases and malignant tumors [12]. In Tibet, the criteria for hypertension diagnosis is based on the 2018 Chinese guidelines for prevention and treatment of hypertension. The prevalence of hypertension in Tibet (55.9\%) is higher than the Chinese national level (29.6\%), and is the highest among all provinces [13, 14]. Moreover, a study reported that the rate of CVD-related morbidity and mortality was higher than in other provinces of China [15]. Our previous survey showed that the prevalence of HT decreased with increasing elevation and increased with advanced age and increasing BMI value [16]. Based on previous studies, the association between altitude and hypertension prevalence is controversial [10, 17] Mingji et al. [10] found that geographic and socioeconomic status had significant effects on the awareness and subsequent treatment and control of hypertension among people living in different altitude areas. The local government of Tibet has been sponsoring free physical examinations for herderfarmers since 2012 [18]. In 2017, more than 3 million urban and rural residents had their health details recorded in the government health information system, equating to coverage of more than $97 \%$ in Tibet [19].

The physical examination program included simple measurements such as height, weight, and blood pressure measurement, and also the sophisticated tests such as vision, blood examination, and echocardiography. Those diagnosed with hypertension receive lifestyle intervention and medical treatment according to the national guidelines [20], and the hypertension information system secured their records. Individuals classified as high risk of hypertension or pre-hypertension are managed promptly at the nearby health center. Health personnel at the local health care center follow hypertensive patients up every three months to check their blood pressure and monitor any complications and side effects of treatment [21]. Patients are transferred to the upper level of medical care if needed.

The researchers conducted two parallel surveys to find the prevalence of hypertension in relation to the 3 levels of geographical altitude in Tibet and to document the epidemiological risk factors for HT, both general and specific to Tibetan people. It was published earlier in February 2020 [16], Another survey, the current report, tried to estimate the coverage of the existing HT screening program provided by the government of Tibet Autonomous Region which required people to come to the health service stations using the local administrative network down to the villages.

Although the administrative data is present for the whole region, information on screening in different altitude areas was lacking. At this moment, there has been no research reporting the coverage of the target population, i.e. the number and percentage of people screened for hypertension in Tibet. As transportation barriers and high altitudes in Tibet complicates the control of hypertension, the evaluation of the program in this area needs further scrutiny. This study aims to assess the coverage and effectiveness of hypertension screening and management in different altitude areas of Tibet.

\section{Materials and methods Study design}

We conducted a stratified cluster survey from September to December 2017 to determine the coverage and effectiveness of hypertension screening and management program in 3 altitude levels of Tibet, and also the determinants of the success of the screening program.

\section{Study setting}

This study was combined within our previous report on the relationship of hypertension prevalence and 
geographic altitude in Tibet [16]. Three different altitude areas were purposively selected: Bomi county of Nyingchi city, Dagze district of Lhasa city, and Nagarze county of Lhokha city. These three areas had an average altitude of $2500 \mathrm{~m}, 4100 \mathrm{~m}$, and $4500 \mathrm{~m}$ above sea level, respectively [22]. Bomi County is the farthest from the capital city (Lhasa), followed by Nagarze county and Dagze District, with average distances from the capital city of 630, 127 , and $50 \mathrm{~km}$, respectively. In Bomi County, the primary sources of income are agriculture, forestry, and tourism. Being close to the capital city of Lhasa, Dageze district is more urbanized, although, in some parts, agriculture is the primary source of income. Nagarze county is situated in south-eastern Tibet, mostly surrounded by hills where animal husbandry has become the primary source of income for residents.

\section{Sample selection}

Two townships located within $50 \mathrm{~km}$ from the center of each county were selected using simple random sampling. Thus, we chose a total of 6 townships as the primary sampling units. The most recent prevalence (p) of hypertension in Lhasa city was $51.2 \%$ [23]. With a twosided, $95 \%$ confidence interval, an error (d) of 0.05 , a design effect (deff) of 1.3, and including 10\% nonrespondents, we required a total of 550 participants in each county by using the following formula. We randomly selected eligible participants from each county. The formula for sample size calculation to get an adequate prevalence of hypertension was:

$$
n=Z_{1-\frac{\alpha}{2}}^{2} p \frac{1-p}{d^{2}}
$$

$n_{\text {Adjust }}=n \times$ deff.

We ran a multistage cluster sampling by randomly selecting 10 administrative villages from 6 townships in the three study areas. The researcher team went to the villages and did participant invitation through the appointment of the head of the village.

\section{Inclusion and exclusion criteria}

Eligibility criteria for participants included age $\geq 18$ years, Tibetan ethnicity, and residents in the village for at least one year. Excluded from this survey were those who had severe mental dysfunction, pregnancy, or severe complications of hypertension.

\section{Data collection}

The researchers invited eligible participants to the nearest local primary health center or village committee offices. After giving informed consent, all study participants were physically examined by trained investigators following standard protocols. Physical measurements included weight, height, and blood pressure. The body weight and height of participants wearing no shoes or overcoat were measured using the Suhong RGZ-120 height and weight scale. Before the first examination of their blood pressure, we allowed participants to relax for at least five minutes in a quiet room. Investigators advised all participants to avoid drinking tea and alcohol, cigarette smoking, over-exercising, and to void urine half an hour before their examination. In this survey, we used an electronic sphygmomanometer with high reliability and validity (Omron HEM-7201 automatic blood pressure monitor) at a high altitude area [24]. Blood pressure was measured twice at $60 \mathrm{~s}$ intervals for all participants. Those who had a discordant blood pressure of greater than ten $\mathrm{mmHg}$ on the previous two measurements had a third measurement taken. The final result was the arithmetic mean of all BP measurements. To explore the participants previously diagnosed with hypertension, we administered self-completed questionnaires and confirmed the results by checking the record books of the participants. The questionnaire and case record form (Supplementary Table 1) used in this study were developed by the researcher team and used in our previous survey in estimating the prevalence of $\mathrm{HT}$ in Tibet reported separately [16].

\section{Variable definitions}

The outcome variables are subjects who were screened for hypertension and among the known hypertension cases, those who were controlled across the different altitude areas in Tibet. Independent variables included socio-demographic characteristics, biological, and behavioral determinants, and history of diseases. Behavioral determinants included the consumption of tobacco and alcohol, and biological factors included body mass index (BMI) defined as the weight $(\mathrm{kg})$ divided by the square of height $\left(\mathrm{m}^{2}\right)$ and waist circumference. According to Chinese BMI classification, the BMI range for overweight is from $24.0-27.9 \mathrm{~kg} / \mathrm{m}^{2}$, and the cut point for obesity is $\geq 28.0 \mathrm{~kg} / \mathrm{m}^{2}[25]$.

We identified those who had regular measurements by community health workers in the hypertension intervention program to determine the screening coverage of hypertension screening. We recorded the results of the routine hypertension screening as hypertension or no hypertension detected by the routine screening by community health workers.

We defined the effectiveness of hypertension screening in terms of retention in care after diagnosis and initiation of treatment [26] as the proportion of those previously diagnosed hypertension by local health workers who had systolic blood pressure $(\mathrm{SBP})<140 \mathrm{mmHg}$ and diastolic blood pressure (DBP) $<90 \mathrm{mmHg}$. 
Individuals previously informed by a doctor or local health worker about their hypertension status, despite their current hypertension status, were considered to have hypertension awareness. Individuals who responded "no" to the question: "In the past, have you received measurement of hypertension by a local doctor or healthcare provider?" and had hypertension during their physical examination, were categorized as unaware hypertension.

The presence of hypertension was defined as $\mathrm{SBP} \geq$ $140 \mathrm{mmHg}$ and/or DBP $\geq 90 \mathrm{mmHg}$, and/or selfreported treatment for hypertension with antihypertensive medications taken in the past two weeks [27].

Participants who answered "yes" to the question "In the past, have you received a diagnosis of hypertension by a local doctor or healthcare provider?" were categorized as previously diagnosed hypertension.

\section{Statistical analysis}

We described the characteristics of the participants in our study by a weighted analysis. We observed the difference in the distribution of age and gender between the study participants and the list of residents in the villages (Supplementary Table 2). We used the survey design to adjust the estimates, and the iterative proportional fitting (raking) to reduce the sampling bias by fitting the data using known demographic characteristics from the 2010 census. We used $\mathrm{R}$ version 3.5.1 (https://cran.r-project.org) to analyze the data. We used the survey-weighted logistic regression models to find factors associated with the screening of hypertension in the past.

A Venn diagram visualizes the overlapping sets of newly discovered hypertension cases by this study, previously diagnosed hypertension by screening program, and those who received antihypertensive treatment in the past, both controlled and uncontrolled states.

Figure 1 schematizes the three groups of people. Those who were covered by this survey are shown in the dotted-lined circle. The solid-lined circle represents those who were previously approached by the screening program. The small dash-dot-lined circle represents those who were screened and received antihypertensive treatment. The segment marked "a" represents those who diagnosed with hypertension but never tested or unscreened hypertension in the past and denoted as unaware hypertension. Uncontrolled hypertension (or diagnosed hypertension in both the survey and screening program) is the summation of segments "b" and "d." Segment "c" represents those who previously had a history of diagnosed hypertension but normal blood pressure in our study. Segments "d" and "e" represent those uncontrolled and controlled hypertensive patients after medical treatment, respectively. Finally, anyone falling

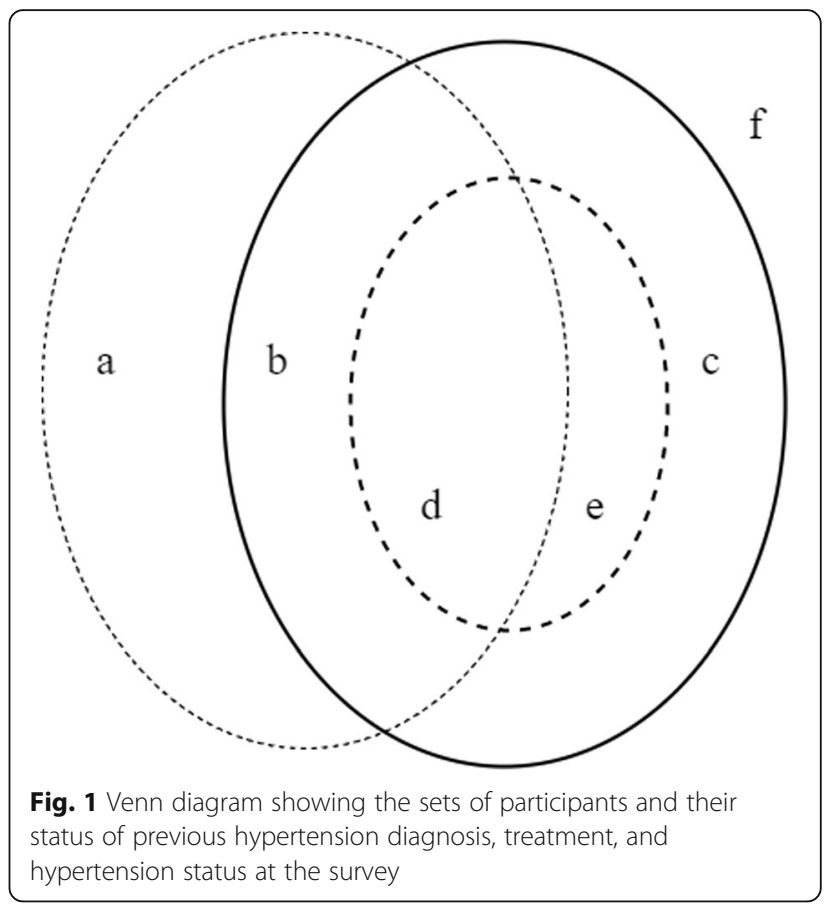

outside the circles marked as " $\mathrm{f}$ " is normotensive or non-hypertensive subjects.

The effective coverage was defined by Shengelia et al. (2005) [28] and later by Ng et al. (2014) [29], as the fraction of potential health gain that was actually delivered to the population through the health system. The calculation of the effective coverage follows the following formula:

$E C_{i j}=U_{i j} Q_{i j} / N_{i j}$

Where subscriptions $i$ and $j$ represent individual and intervention. $E C_{i j}$ is the effective coverage of individual $i$ with intervention $j$. In our case, where the intervention is only the HT screening program, thus, $i$ remains in the formula, and $j$ is omitted. Then,

$E C_{i=} U_{i^{*}} Q_{i} / N_{i}$, or $E C=U_{*} Q / N$, in a simple term.

Where $Q$ is the quality or health gain ratio. $U$ is the utilization of health service and refers to the probability that the individual with a need will receive the intervention. $N$ is the need indicator, which refers to individuals who will gain actual benefits from receiving or true need; if $N=1$ is the true need for receiving the healthcare services and $N=O$ for individual no need for coverage. In this survey, we calculated the effective coverage of HT screening by replacing $U$ with the coverage of HT screening program, and $Q / N$ is the effectiveness of HT treatment, both by medical and lifestyle modification, among the screened population.

Variables excluded from the final multivariate model were those with a univariate $p$-value greater than 0.2 . Factors assisting control of hypertension programs were identified using survey-weighted logistic regression 
modeling and determined based on a backward stepwise process and included only variables with a p-value less than 0.05 .

\section{Results}

Among a total of 1636 study participants, 1020 (62.3\%) were female. The un-weighted characteristics of participants by the status of hypertension screening in the past are shown in Supplementary Table 2. Local health workers screened a total of 1539 (94.1\%) participants from the screening program, of which $37.4 \%$ were diagnosed with hypertension.

Table 1 shows the weighted results applied to the whole population. Almost 95\% of residents were previously screened for hypertension by a hypertension intervention program or free physical examination project, especially in the low altitude area, above $97 \%$ of the participants were screened. Gender, age, occupation, alcohol use, and altitude were factors significantly associated with prior screening status. Among those prior screened, 24.7\% (95\% CI: 22.1-27.3\%) were diagnosed with hypertension. Hypertension status significantly associated with gender, age group, marital status, education, BMI level, and altitude.

Table 2 summarizes the risk factors of previous screening for hypertension from the multivariate analysis. Gender, alcohol consumption, and living altitude were significantly associated with the last screening for hypertension, after adjustment for other potential confounding factors. Females and alcohol drinkers were more likely to be screened while the proportion of the population screened declined with increasing altitude.

Figure 1 and Table 3 illustrate the proportions of participants with current hypertension and previous hypertensive diagnosis and treatment. The overall unaware hypertension rate was $12.6 \%$, and as shown in Table 3, the highest rate occurred in the middle altitude area (16.9\%). The overall uncontrolled hypertension rate was $71.3 \%$, and the low altitude area had the highest rate.

In this regard, the overall rate of hypertension controlled by non-medication prescription was $39.5 \%$, and the coverage tended to be better in the high altitude areas with no statistical significance. Among those with medical treatment, the overall controlled hypertensive rate was $24.9 \%$, and the rates were similar in the three altitude levels. In addition, we observe there were differences in the effective coverage of HT screening in different areas. The overall effective coverage of HT screening was at $27.2 \%$. The proportion of effective coverage was slightly higher at high altitude area. There is likely a positive correlation between effective coverage and the effectiveness of HT screening in different areas.

Table 4 shows factors associated with controlled hypertension (overall, by treatment, and by lifestyle modification) among those with previously diagnosed hypertension. Altitude level and age were significantly associated with overall controlled hypertension, while age and gender were significantly related to controlled hypertension by treatment and lifestyle modification, respectively. Those who lived in the middle and high altitudes and were aged $18-39$ years were more likely to control their hypertension.

Hypertension control via drugs was more likely among people aged under 40 years and among those living in middle altitude areas, while hypertensive control via lifestyle modification was more likely among those who lived in high altitudes without statistically significant. Females were also more likely to control their hypertension with lifestyle modification.

\section{Discussion}

The proportion of hypertension screening was highest among Tibetans who lived at low altitudes. Other factors, such as gender, alcohol use, and BMI, also played some role in the coverage of hypertension screening. Around $87 \%$ of Tibetans aged over 18 years were screened for hypertension, and $28.7 \%$ of those diagnosed with hypertension had it under control. Despite the high screening coverage, the screening program's effectiveness was considered acceptable at around $30 \%$ of controlled hypertension. A higher proportion of hypertension awareness and controlled hypertension was found among those living in high altitude areas. The overall effective coverage of HT screening was only at $27.2 \%$. The program's effectiveness was dependent on altitude, age, and gender. Younger aged residents, females, and those who lived in the middle and high altitudes tended to have higher control rates.

More than $95 \%$ of the participants living at the low and middle altitude areas were previously screened by a hypertension intervention program or free physical examination project, while the screening rate was over $90 \%$ for people living at high altitudes. This finding indicates that the coverage of the hypertension screening program was high in all three altitude levels. The fact that townships in the low altitude areas are more developed than in the high areas could explain the higher screening coverage in the low and middle elevation areas where people and health care personnel have been adapting to the Western Development Strategy [30].

High coverage of hypertension screening was more prevalent among females and alcohol drinkers as shown in Table 2. Studies assessing the population coverage of hypertensive screening demonstrated that females had a slightly more significant proportion of hypertension testing than males [31, 32]. We found no effect of age on the screening coverage. One of the reasons was that age was independent of the demand for the health care of 
Table 1 Characteristics of the participants by the screening of hypertension in the past, in estimated number of Tibetan people and percentage and 95\% confidence interval

\begin{tabular}{|c|c|c|c|c|c|c|c|c|c|c|}
\hline \multirow{5}{*}{$\begin{array}{l}\text { Characteristics } \\
\end{array}$} & \multicolumn{9}{|c|}{ History of hypertension screening } & \multirow{3}{*}{$\begin{array}{l}p- \\
\text { value }\end{array}$} \\
\hline & \multicolumn{7}{|c|}{ Screened } & \multirow{2}{*}{\multicolumn{2}{|c|}{ Not screened }} & \\
\hline & \multicolumn{7}{|c|}{ Hypertension } & & & \\
\hline & Total & & Yes & & No & & & & & \\
\hline & Est. N & $\%(95 \% \mathrm{Cl})$ & Est. $N$ & $\%(95 \% \mathrm{Cl})$ & Est. N & $\%(95 \% \mathrm{Cl})$ & $p$ - value & Est. $N$ & $\%(95 \% \mathrm{Cl})$ & \\
\hline Overall & 64,227 & $94.9(93.2-96.6)$ & 15,881 & $24.7(22.1-27.3)$ & 48,346 & $75.3(72.7-77.9)$ & & 3426 & $5.1(3.4-6.8)$ & \\
\hline Gender & & & & & & & 0.003 & & & 0.027 \\
\hline Male & 32,613 & $93.4(90.3-96.4)$ & 9835 & $30.2(25.1-35.2)$ & 22,778 & $69.8(64.8-74.9)$ & & 2309 & $6.6(3.4-9.7)$ & \\
\hline Female & 31,613 & $96.6(95.3-97.9)$ & 6045 & $19.1(15.4-22.9)$ & 25,567 & $80.9(77.1-84.6)$ & & 1116 & $3.4(2.1-4.7)$ & \\
\hline Age group & & & & & & & $<0.001$ & & & 0.040 \\
\hline $18-39$ & 38,415 & $96.8(94.2-99.4)$ & 4393 & $11.4(7.6-15.3)$ & 34,022 & $88.6(84.7-92.4)$ & & 1275 & $3.2(0.6-5.8)$ & \\
\hline $40-59$ & 19,226 & $92.3(90.2-94.4)$ & 7013 & $36.5(32.9-40.1)$ & 12,212 & $63.5(59.9-67.1)$ & & 1598 & $7.7(5.6-9.7)$ & \\
\hline $60+$ & 6585 & $92.3(88.7-95.8)$ & 4473 & $67.9(61.7-74.2)$ & 2111 & $32.1(25.8-38.3)$ & & 552 & $7.7(4.2-11.3)$ & \\
\hline Marital status & & & & & & & $<0.001$ & & & 0.468 \\
\hline Single/separated & 7858 & $96.9(92.4-100)$ & 3595 & $45.8(36.0-55.5)$ & 4262 & $54.2(44.5-64.0)$ & & 252 & $3.1(0-7.0)$ & \\
\hline Married & 56,368 & $94.7(92.8-96.5)$ & 12,284 & $21.8(19.1-24.5)$ & 44,083 & $78.2(75.5-80.9)$ & & 3175 & $5.3(3.5-7.1)$ & \\
\hline Education & & & & & & & 0.031 & & & 0.319 \\
\hline None & 30,351 & $96.3(95.1-97.4)$ & 8630 & $28.4(24.7-32.2)$ & 21,720 & $71.6(67.8-75.3)$ & & 187 & $3.7(2.5-4.9)$ & \\
\hline Primary school & 26,191 & $93.1(89.8-96.4)$ & 6210 & $23.7(19.2-28.2)$ & 19,981 & $76.3(71.8-80.8)$ & & 487 & $6.9(3.5-10.2)$ & \\
\hline Middle school and above & 7683 & $96.1(89.4-100)$ & 1040 & $13.5(4.4-22.6)$ & 6643 & $86.4(77.4-95.6)$ & & 279 & $3.9(0.0-10.6)$ & \\
\hline Occupation & & & & & & & 0.096 & & & 0.020 \\
\hline Agriculturalist & 55,782 & $96.1(94.8-97.4)$ & 13,343 & $23.9(21.2-26.6)$ & 42,438 & 76.1 (73.4-78.8) & & 2240 & $3.9(2.6-5.2)$ & \\
\hline Herdsman & 4294 & $87.4(76.5-98.4)$ & 1656 & $38.6(24.7-52.5)$ & 2638 & $61.4(47.5-75.3)$ & & 617 & $12.5(1.6-23.5)$ & \\
\hline Other & 4149 & $87.9(74.8-100)$ & 881 & $21.2(7.6-34.9)$ & 3269 & $78.8(65.1-92.4)$ & & 569 & $12.1(0--25.2)$ & \\
\hline Income (CNY), & & & & & & & 0.283 & & & 0.760 \\
\hline$\leq 2500$ & 54,426 & $95.0(93.3-96.7)$ & 13,879 & $25.5(22.7-28.3)$ & 40,546 & $74.5(71.7-77.3)$ & & 2.863 & $5.0(3.3-6.7)$ & \\
\hline $2501-5000$ & 7906 & $93.9(87.3-100)$ & 1767 & $22.3(13.3-31.4)$ & 6139 & $77.7(68.6-86.7)$ & & 513 & $6.1(0-12.6)$ & \\
\hline$\geq 5001$ & 1894 & $97.4(92.3-100)$ & 235 & $12.4(1.0-23.8)$ & 1659 & 87.7 (76.2-99.0) & & 49 & $2.6(0-7.6)$ & \\
\hline Tobacco use & & & & & & & 0.902 & & & 0.325 \\
\hline Yes & 17,447 & $93.4(89.2-97.8)$ & 4260 & $24.4(18.8-30.0)$ & 13,187 & $75.6(70.0-81.2)$ & & 1224 & $6.5(2.3-10.8)$ & \\
\hline No & 46,779 & $95.5(93.8-97.1)$ & 11,620 & $24.8(21.7-28.0)$ & 35,159 & $75.2(72.0-78.3)$ & & 2202 & $4.5(2.8-6.1)$ & \\
\hline Alcohol use & & & & & & & 0.693 & & & 0.013 \\
\hline Yes & 17,133 & $97.5(96.0-99.0)$ & 4048 & $23.6(17.0-30.2)$ & 13,085 & 76.4 (69.7-83.0) & & 443 & $2.5(1.0-4.0)$ & \\
\hline No & 47,093 & $94.0(81.7-96.3)$ & 11,833 & $25.1(22.3-28.0)$ & 35,260 & $74.9(72.4-77.7)$ & & 2983 & $6.0(3.7-8.3)$ & \\
\hline $\mathrm{BMI}\left(\mathrm{kg} / \mathrm{m}^{2}\right)$ & & & & & & & $<0.001$ & & & 0.112 \\
\hline$\leq 23.9$ (Normal) & 37,148 & $96.2(94.4-98.1)$ & 6031 & $16.2(13.6-18.9)$ & 31,117 & $83.8(81.1-86.4)$ & & 1459 & $3.7(1.9-5.6)$ & \\
\hline 24-27.9 (Overweight) & 18,494 & 94.4 (91.3-97.6) & 5609 & $30.3(24.8-35.9)$ & 12,885 & $69.7(64.1-75.2)$ & & 1095 & $5.6(2.4-8.7)$ & \\
\hline$\geq 28.0$ (Obese) & 8583 & $90.8(84.0-97.6)$ & 4240 & $49.4(39.2-59.6)$ & 4343 & $50.6(40.4-60.8)$ & & 871 & $9.2(2.4-16.0)$ & \\
\hline Altitude level (m) & & & & & & & $<0.001$ & & & 0.002 \\
\hline Low (2500-3499) & 24,892 & 97.7 (96.0-99.4) & 8405 & $33.8(28.5-39.0)$ & 16,486 & $66.2(61.0-71.5)$ & & 585 & $2.3(0.6-4.0)$ & \\
\hline Middle (3500-4399) & 10,082 & 96.4 (94.9-97.9) & 2393 & $23.7(18.7-28.8)$ & 7689 & $76.3(71.2-81.3)$ & & 378 & $3.6(2.1-5.1)$ & \\
\hline High (4400-5300) & 29,252 & $92.2(89.0-95.5)$ & 5083 & $17.4(13.7-21.0)$ & 24,169 & $82.6(79.0-86.3)$ & & 2463 & $7.8(4.5-11.0)$ & \\
\hline
\end{tabular}


Table 2 Factors associated with previous screening for hypertension

\begin{tabular}{|c|c|c|c|}
\hline Variable & $\begin{array}{l}\text { Percent } \\
\text { Screened } \\
(95 \% \mathrm{Cl})\end{array}$ & $\begin{array}{l}\text { Odds ratio } \\
(95 \% \mathrm{Cl})\end{array}$ & *P-value \\
\hline Total & $94.9(93.2-96.6)$ & & \\
\hline \multicolumn{4}{|l|}{ Gender } \\
\hline Female & $96.6(95.3-97.9)$ & Ref. & 0.034 \\
\hline Male & $93.4(90.3-96.4)$ & $0.45(0.21-0.95)$ & \\
\hline Age group & & & 0.143 \\
\hline $18-39$ & 96.7 (94.2-99.4) & Ref. & \\
\hline $40-59$ & $92.3(90.3-94.4)$ & $0.49(0.20-1.24)$ & \\
\hline $60+$ & $92.3(88.7-95.8)$ & $0.47(0.17-1.32)$ & \\
\hline Occupation & & & 0.335 \\
\hline Agriculturalist & $96.1(94.8-97.4)$ & Ref. & \\
\hline Herdsman & $87.4(76.5-98.4)$ & $0.57(0.19-1.74)$ & \\
\hline Other & $87.9(74.8-100.0)$ & $0.40(0.10-1.57)$ & \\
\hline Alcohol use & & & 0.004 \\
\hline No & $94.0(81.7-96.3)$ & Ref. & \\
\hline Yes & 97.5 (96.0-99.0) & $3.39(1.36-8.45)$ & \\
\hline $\mathrm{BMI}\left(\mathrm{kg} / \mathrm{m}^{2}\right)$ & & & 0.055 \\
\hline$\leq 23.9$ (Normal) & $96.2(94.4-98.1)$ & Ref. & \\
\hline $\begin{array}{l}\text { 24-27.9 } \\
\text { (Overweight) }\end{array}$ & $94.4(91.3-97.6)$ & $0.58(0.27-1.25)$ & \\
\hline$\geq 28.0$ (Obese) & $90.8(84.0-97.7)$ & $0.29(0.10-0.87)$ & \\
\hline Altitudes level (m) & & & 0.010 \\
\hline Low (2500-3499) & $97.7(96.0-99.4)$ & Ref. & \\
\hline Middle (3500-4399) & $96.4(94.9-97.9)$ & $0.59(0.26-1.36)$ & \\
\hline High (4400-5300) & $92.2(89.0-95.5)$ & $0.28(0.10-0.77)$ & \\
\hline
\end{tabular}

Note: Ref.: the reference group of each predictor. ${ }^{*}$ Likelihood ratio test Abbreviations: $\mathrm{Cl}$ confidence interval, $B M I$ body mass index

individuals. The health care system and its personnel actively ran the program based on the household registration.

In our study, those who drank alcohol tended to be more engaged in the hypertension screening program. The Tibetan government set up the hypertension screening program to find people with high blood pressure. It is relatively easy for local health personnel to target those who drink since they tend to socialize in public places. It is a usual practice of health care personnel to find people with hypertension among vulnerable groups and give them appropriate treatment. As a result, the program may have recruited more drinkers than expected. However, it can result in a bias in estimating the attitude of people to come for screening. We don't know whether or not drinkers have changed their drinking behavior and reduced the amount of alcohol intake. Alcohol drinking culture is still prevalent in Tibet, for people to show their hospitality and to reduce stress, facilitate social interaction, and foster good interpersonal relationships [33, 34]. So far, there has been no program for alcohol consumption reduction in Tibet. Experiences from European countries showed that even with the existence of screening and appropriate interventions for hazardous alcohol use and use disorders, a lack in implementing the measures prevented success in noncommunicable disease control [35].

We found that the hypertension awareness rate was 87.3\% (95\% CI: 84.9-89.8\%), and it was higher than the rate in Lhasa reported in 2013 of 63.5\% [36]. Our finding was also higher than the results of other studies conducted in different regions of China [6, 14], and among Canadian adults [37]. Financial affordability acts as a strong barrier compared to physical accessibility and acceptability of the hypertension screening program in some countries [38], but not in Tibet, where hypertension screening has been a part of the universal health benefits package since 2012 [19]. In general, the awareness of health and healthcare utilization is related to distance to and convenience of the health service [28].

The hypertensive awareness rate was the highest at high altitude areas where it was 90.4\% (95\%CI: $86.9-$ 94.0\%). At high elevation in Tibet, people live at a long distance from the health facilities. Those living at high altitudes are likely the target of health researches and various kinds of services by the government and academic institutes, and they are therefore more likely to be approached by the health services for hypertension screening.

The overall control rate of hypertension in our study was $28.7 \%$. It was about three times higher than the finding of $9.6 \%$ reported in a study that was conducted in five provinces in southwest China [39]. The overall hypertension control rate increased with increasing altitude. The HT control rate, both on the whole and among those who took medical treatment, was higher in young people than the elderly. Such a better hypertension control among young persons is different from the findings in China [40] and in the United States [41], while the results in Pakistan were similar to our study [42]. In Tibet, health personnel have been actively inviting villagers to participate in hypertension check-up procedures. The study from Pakistan mentioned 'hypertension screening camps' which implies the active recruitment of participants. The method used to recruit participants in hypertension screening, therefore, seems to affect the relationship between age and the control rate of hypertension.

The effective coverage of HT screening in this study period was a little over a quarter (27.2\%). It is lower than the effective coverage of HT screening in Thailand at $49.9 \%$ [31]. The main reason for the low effective coverage was a big portion of those who found HT by 
Table 3 Hypertension awareness and control status in the Tibetan population stratified by altitude

\begin{tabular}{|c|c|c|c|c|c|c|c|c|c|}
\hline \multirow[t]{3}{*}{ Outcome variable } & \multirow{2}{*}{\multicolumn{2}{|c|}{ Total }} & \multicolumn{6}{|c|}{ Altitude } & \multirow{3}{*}{$\begin{array}{l}P \text { - } \\
\text { value }\end{array}$} \\
\hline & & & \multicolumn{2}{|c|}{$\begin{array}{l}\text { Low } \\
(2500-3499 \mathrm{~m})\end{array}$} & \multicolumn{2}{|c|}{$\begin{array}{l}\text { Middle } \\
(3500-4399 \mathrm{~m})\end{array}$} & \multicolumn{2}{|c|}{$\begin{array}{l}\text { High } \\
(4400-5300 \mathrm{~m})\end{array}$} & \\
\hline & $\mathrm{N}$ & $\%(95 \% \mathrm{Cl})$ & $\mathbf{N}$ & $\%(95 \% \mathrm{Cl})$ & $\bar{N}$ & $\%(95 \% \mathrm{Cl})$ & $\bar{N}$ & $\%(95 \% \mathrm{Cl})$ & \\
\hline \multicolumn{9}{|c|}{ Awareness rate of hypertension among those discovered in this study } & $0.045^{*}$ \\
\hline Unaware (a) & 8554 & $12.6(10.2-15.1)$ & 3757 & $14.7(10.2-19.3)$ & 1767 & $16.9(12.5-21.3)$ & 3030 & $9.6(6.0-13.1)$ & \\
\hline Aware $(b+c+d+e+f)$ & 59,098 & $87.3(84.9-89.8)$ & 21,720 & $85.3(80.7-89.8)$ & 8693 & $83.1(78.7-87.5)$ & 28,684 & $90.4(86.9-94.0)$ & \\
\hline \multicolumn{9}{|c|}{ Hypertension control status among those previously diagnosed with hypertension } & 0.150 \\
\hline Uncontrolled $(b+d)$ & 11,326 & $71.3(65.4-77.2)$ & 6416 & $76.3(67.4-85.2)$ & 1610 & $67.3(56.8-77.8)$ & 3301 & $64.9(54.6-75.2)$ & \\
\hline Controlled $(c+e)$ & 4554 & $28.7(22.8-34.6)$ & 1990 & $23.7(14.7-32.6)$ & 783 & $32.7(22.2-43.2)$ & 1782 & $35.1(24.8-45.3)$ & \\
\hline \multicolumn{9}{|c|}{ Hypertension control status among those not prescribed anti-hypertension medication } & 0.321 \\
\hline Uncontrolled (b) & 2471 & $60.5(49.0-72.0)$ & 1041 & $66.7(48.9-84.5)$ & 494 & $70.9(47.5-94.2)$ & 936 & $51.2(34.0-68.5)$ & \\
\hline Controlled (c) & 1614 & $39.5(28.0-51.0)$ & 521 & $33.3(15.5-51.1)$ & 203 & $29.1(5.8-52.5)$ & 890 & $48.8(31.5-66.0)$ & \\
\hline \multicolumn{9}{|c|}{ Hypertension control status among those who were prescribed anti-hypertension medication } & 0.302 \\
\hline Uncontrolled (d) & 8855 & $75.1(68.2-81.9)$ & 5374 & $78.5(68.3-88.8)$ & 1116 & $65.8(54.6-77.0)$ & 2364 & $72.6(61.3-84.0)$ & \\
\hline Controlled (e) & 2940 & $24.9(18.1-31.8)$ & 1469 & $21.5(11.2-31.7)$ & 579 & $34.2(23.0-45.4)$ & 892 & $27.4(16.0-38.7)$ & \\
\hline Effective coverage of HT screening & & $28.7(22.8-34.6)$ & & $43.7(30.8-56.5)$ & & $17.2(10.1-24.3)$ & & $39.1(27.5-50.8)$ & 0.154 \\
\hline
\end{tabular}

Note: The data are weighted percentage with $95 \% \mathrm{Cl}$ shown in brackets; Pearson's chi-square test with Rao-Scott adjustment was used to compare

screening got insufficient control of HT. We found the effectiveness of hypertension control by lifestyle modification was better in females than males (Table 4). The phenomenon happened in the reports from the United States and Africa [40, 43]. A meta-analysis of studies did not document gender differences in hypertension treatment results [44]. The conclusion was that socioeconomic and cultural factors could explain such differences by gender. Studies in the United States and Africa mentioned a better practice of health-seeking behavior among females for chronic disease than males [32, 45]. Such a better health-consciousness among females may explain the finding that they got better control from lifestyle modification. However, the issue of gender differences in the effectiveness of control of hypertension is still controversial [44].

The high coverage of the active HT screening program by healthcare workers with a low controlled hypertension and effective coverage (Table 3) means that the effective behavioral modification and treatment procedures need to be improved. Studies showed nonadherence to HT control procedures and lack of healthcare workers were mentioned [46, 47]. We have not explored those two factors in Tibetan context.

Table 4 Factors associated with controlled hypertension among those with previous hypertension

\begin{tabular}{|c|c|c|c|c|c|c|}
\hline \multirow[t]{2}{*}{ Variables } & \multicolumn{2}{|c|}{$\begin{array}{l}\text { Overall controlled } \\
\text { hypertension }\end{array}$} & \multicolumn{2}{|c|}{$\begin{array}{l}\text { Controlled hypertension by medical } \\
\text { treatment }\end{array}$} & \multicolumn{2}{|c|}{$\begin{array}{l}\text { Controlled hypertension by lifestyle } \\
\text { modification }\end{array}$} \\
\hline & aOR $(95 \% \mathrm{Cl})$ & $P^{*}$ & aOR $(95 \% \mathrm{Cl})$ & $P^{*}$ & aOR $(95 \% \mathrm{Cl})$ & $P^{*}$ \\
\hline Altitude level (m) & & 0.030 & & 0.080 & & 0.115 \\
\hline Low (2500-3499) & 1.00 & & 1.00 & & 1.00 & \\
\hline Middle (3500-4399) & $1.98(1.01-3.90)$ & & $2.70(1.38-5.28)$ & & $1.51(0.34-6.76)$ & \\
\hline High (4400-5300) & $2.19(1.08-4.43)$ & & $1.80(0.71-4.59)$ & & $2.91(1.05-8.05)$ & \\
\hline Age group (year) & & 0.002 & & 0.017 & & 0.088 \\
\hline $18-39$ & 1.00 & & 1.00 & & 1.00 & \\
\hline $40-59$ & $0.34(0.15-0.78)$ & & $0.33(0.11-0.94)$ & & $0.45(0.15-1.35)$ & \\
\hline $60+$ & $0.23(0.09-0.54)$ & & $0.23(0.08-0.68)$ & & $0.25(0.07-0.89)$ & \\
\hline Gender & & 0.161 & & - & & 0.019 \\
\hline Female & 1.00 & & - & & 1.00 & \\
\hline Male & $0.66(0.37-1.17)$ & & - & & $0.31(0.12-0.82)$ & \\
\hline
\end{tabular}

*Likelihood ratio test $\mathrm{p}$-value, $a O R$ adjusted odds ratio 
This study presents a comprehensive analysis of the coverage and effectiveness of hypertension screening and control at different altitude levels of Tibet.

\section{Limitations}

In a field survey that asks people to participate in the study, it has a high tendency of missing those with severe diseases such as those with CVD complications. Hence, the estimates we reported may be biased towards mildly and moderately severe disease. There were advantages in approaching people in situ at the villages but men working in cities and children studying in schools could be missed. Although we applied post-hoc weights to different age groups and gender by raking procedure, such the adjustment could bring bias in the computation. Also, we could not determine in detail the specific lifestyle modification reported by participants such as daily salt consumption, the number of alcoholic drinks, and the physical activity level. Another limitation in our study is that the study ran under the structure of the healthcare system of the Tibet Government where it is taking care of disease and high-risk persons. Thus, it is unavoidable that we would recruit participants with a high risk of $\mathrm{HT}$ and other chronic diseases. It requires further studies to consider the pre-HT, suspected HT cases, and intervention effectiveness, including treatment and CVD risk assessment.

\section{Conclusion}

The study confirmed a high coverage of the hypertension screening program, especially at the low altitude areas, but the effectiveness of the program is improvable. The HT control effectiveness seems to be better among younger females regardless of taken antihypertension medicine or keep a healthy lifestyle or consideration to both. It is possible to run a co-intervention program to improve the adherence to hypertension treatment along with the existing HT screening routines.

\section{Supplementary Information}

The online version contains supplementary material available at https://doi. org/10.1186/s12889-020-09858-0.

Additional file 1: Supplementary Table 1 Questionnaire and record form for physical measurement.

Additional file 2: Supplementary Table $\mathbf{2}$ Characteristics of the participants by screening of hypertension in the past (raw data, $N=$ 1636)

\section{Abbreviations}

HT: Hypertension; BP: Blood pressure; CVD: Cardiovascular diseases; BMI: Body mass index; SBP: Systolic blood pressure; DBP: Diastolic blood pressure:

$\mathrm{Cl}$ : Confidence interval

\section{Acknowledgments}

We thank all participants for their cooperation in joining the study. We are grateful to the Bomi county disease control center, the health bureau at
Dageze District center, and Nagarze county for supporting the study. We thank all the health workers who gave their support during the data collection process. Finally, we would like to express our thanks to those students from the medical college of Tibet University who gave their valuable time in the assistance of data collection.

\section{Authors' contributions}

CS designed the study, collection the raw data, performed the analysis, drafted the initial manuscript, interpreted the data, reviewed and revised the manuscript; CV contributed to the study design, writing manuscript guided; SW, DM and CZ were contributed to data collection; DJ and OL were contributed to the study design and acquisition of funding; HS helped in data interpretation, revised and approved the final manuscript as submitted. All authors have read and approved the manuscript.

\section{Funding}

This study was funded by the grants of Natural Science Foundation Tibet Autonomic Region of China (grant numbers: XZ2019ZR G-15(Z)), the youth development of Tibet University - growth plan (grant no. ZDCZJH20-13) and the youth development of medicine college of Tibet University (grant numbers: 2019KYPY12). This study also is part of the first author's thesis in partial fulfilment of the requirements for a Ph.D. at Prince of Songkla University, Thailand, and the China Medical Board under the project "A second collaborative program to improve the health research capacity of western medical universities in China and Prince of Songkla University (PSU)."

\section{Availability of data and materials}

The datasets generated and/or analyzed during the current study are not publicly available due to confidentiality, but data is accessible from the corresponding author on reasonable request.

\section{Ethics approval and consent to participate}

Research has been performed in accordance with the Declaration of Helsinki. The study was approved by the Ethical Review Committee from Prince of Songkla University, Thailand (REC: 60-114-18-5) and the letter of permission of Tibet University. All invited persons had a right to agree to participate in the study using the written informed consent and were informed that they could withdraw from the study at any time.

It was voluntary for the patients to answer the questionnaire, and they had the right to withdraw their undertaking of participation at any time. All the answers were treated strictly confidential, and the patients were guaranteed full anonymity.

\section{Consent for publication}

Not applicable.

\section{Competing interests}

The author(s) declared no potential competing interests with respect to the research, authorship, and/or publication of this article.

\section{Author details}

${ }^{1}$ Medical College, Tibet University, Lhasa 850002, China. ${ }^{2}$ Epidemiology Unit, Faculty of Medicine, Prince of Songkla University, Hat Yai, Songkhla 90110, Thailand. ${ }^{3}$ Bomi county centers for disease control and prevention, Nyingchi 860300, China. ${ }^{4}$ Dagze district centers for disease control and prevention, Lhasa 850100 , China. ${ }^{5}$ Nagarze county centers for disease control and prevention, Lhokha 851100 , China.

Received: 8 March 2020 Accepted: 9 November 2020

Published online: 06 January 2021

\section{References}

1. Mills KT, Bundy JD, Kelly TN, Reed JE, Kearney PM, Reynolds K, et al. Global disparities of hypertension prevalence and control: a systematic analysis of population-based studies from 90 countries. Circulation. 2016;134(6):441-50.

2. Centers for Disease Control and Prevention. Vital signs: prevalence, treatment, and control of hypertension--United States, 1999-2002 and 2005-2008. MMWR Morbidity and Mortality Weekly Rep. 2011:60(4):103-8.

3. Goldman L, Schafer Al. Goldman's Cecil medicine E-book: expert consult premium edition--enhanced online features and print, Single Volume: Elsevier Health Sciences; 2011. 
4. Chen W, Gao R, Liu L, Zhu M, Wang W, Wang Y, et al. Report on Cardiovascular Diseases in China (2014). In: Xiaoqun H, editor. Encyclopedia of China Publishing House: National Center for Cardiovascular Diseases, China; 2015. p. 182.

5. Wu Y. Research progress on epidemiology of hypertension and its risk factors in Chinese population [in Chinese]. Bull Med R. 2003;32(12):27-9.

6. Wu Y, Huxley R, Li L, Anna V, Xie G, Yao C, et al. Prevalence, awareness, treatment, and control of hypertension in China: data from the China National Nutrition and health survey 2002. Circulation. 2008;118(25):2679-86.

7. Li Y, Wang L, Jiang Y, Li X, Zhang M, Hu N. Prevalence of hypertension among Chinese adults in 2010[in Chinese]. Zhonghua Yufang Yixue Zazhi. 2012:46(5):409-13.

8. Hu R, Zou H, Shen C, Heng F. Health care system reform in China: issues, challenges and options. Beijing: China Economics and Management Academy, Central University of Finance and Economics; 2011.

9. Communist Party of China Central Committee. Implementation plan for the recent priorities of the health care system reform (2009-2011). In. Volume 38, edn. Beijing: People's Publishing House, PRC; 2009.

10. Mingji C, Onakpoya IJ, Perera R, Ward AM, Heneghan CJ. Relationship between altitude and the prevalence of hypertension in Tibet: a systematic review. Heart. 2015;101(13):1054-60.

11. Tibet Autonomous Region Bureau of Statistics. Tibet statistical yearbook 2015 [in Chinese]. Beijing: China Statistics Press; 2015.

12. Zhuoma P, Jinlei Q, Cangjue G, Yajie L. Analysis on major death causes and disease burden in residents in Tibet, 2015. Disease Suveillance. 2019;30(01):66-9.

13. Zhao X, Li S, Ba S, He F, Li N, Ke L, et al. Prevalence, awareness, treatment, and control of hypertension among herdsmen living at 4,300 $\mathrm{m}$ in Tibet. Am J Hypertens. 2012;25(5):583-9.

14. Wang J, Zhang L, Wang F, Liu L, Wang H. Prevalence, awareness, treatment, and control of hypertension in China: results from a national survey. Am J Hypertens. 2014;27(11):1355-61.

15. Hu Y, Yao C, Wang W, Hu J, He Y, Zhai F. Survey on the prevalence of hypertension in different ethnic groups in China in 2002 [in Chinese]. Wei Sheng Yan Jiu = J Hyg Res. 2006;35(5):573-5.

16. Song C, Chongsuvivatwong V, Zhu Luo Bu O, Ji D, Sang Zhuo Ma B, Sriplung $\mathrm{H}$. Relationship between hypertension and geographic altitude: a cross-sectional survey among residents in Tibet. J Int Med Res. 2020;48(2): 300060520903645

17. Fiori G, Facchini F, Pettener D, Rimondi A, Battistini N, Bedogni G. Relationships between blood pressure, anthropometric characteristics and blood lipids in high-and low-altitude populations from Central Asia. Ann Hum Biol. 2000;27(1):19-28.

18. China Daily. Development and progress of Tibet. Xinhua News Agency: Beijing; 2013. http://www.chinadaily.com.cn/kindle/2013-10/23/content_1 7052580.htm.

19. Cheng $Y$. Three million people in Tibet received free physical examinations for seven consecutive years [in Chinese]. Xin Hua Net: Lhasa; 2018. http:// www.xinhuanet.com/local/2018-04/07/c_1122645827.htm.

20. National Grassroots Hypertension Management Office. 2017 national guidelines for the prevention and management of hypertension at the grassroots level. Bei Jing: National Cardiovasculour Disease Center; 2017.

21. Liu L. 2010 Chinese guidelines for the management of hypertension [in Chinese]. Chin J Hypertens. 2011;19(7):701-43.

22. Wikipedia. Tibet Autonomous Region. https://en.wikipedia.org/wiki/Tibet_ Autonomous_Region.

23. Zheng X, Yao DK, Zhuo-Ma CR, Tang J, Wang TR, Zhang HH, Wang LX Prevalence, self-awareness, treatment, and control of hypertension in Lhasa, Tibet. Clin Exp Hypertens. 2012;34(5):328-33.

24. Cho K, Tian M, Lan Y, Zhao X, Yan LL. Validation of the Omron HEM-7201 upper arm blood pressure monitor, for self-measurement in a high-altitude environment, according to the European Society of Hypertension International Protocol revision 2010. J Hum Hypertens. 2013;27(8):487-91.

25. Zhou BF. Effect of body mass index on all-cause mortality and incidence of cardiovascular diseases--report for meta-analysis of prospective studies open optimal cut-off points of body mass index in Chinese adults. Biomed Environ Sci. 2002;15(3):245-52.

26. Schmidt BM, Durão S, Toews I, Bavuma CM, Meerpohl JJ, Kredo T. Screening strategies for hypertension: a systematic review protocol. BMJ Open. 2019; 9(1):e025043.

27. Chobanian AV, Bakris GL, Black HR, Cushman WC, Green LA, Izzo JL Jr, et al. The seventh report of the joint national committee on prevention, detection, evaluation, and treatment of high blood pressure: the JNC 7 report. JAMA. 2003;289(19):2560-71.

28. Shengelia B, Ajay T, Adams OB, Murray CJL. Access, utilization, quality, and effective coverage: an integrated conceptual framework and measurement strategy. Soc Sci Med. 2005;61(1):97-109.

29. Ng M, Fullman N, Dieleman JL, Flaxman AD, Murray CJ, Lim SS. Effective coverage: a metric for monitoring universal health coverage. PLoS Med. 2014;11(9):e1001730.

30. Goldstein MC, Childs G, Wangdui P. Bei Jing's "people first" development initiative for the Tibet autonomous Region's rual sector-a case study from the ShiGaTse area. Chin J. 2010;63:57-75.

31. Charoendee K, Sriratanaban J, Aekplakorn W, Hanvoravongchai P. Assessment of population coverage of hypertension screening in Thailand based on the effective coverage framework. BMC Health Serv Res. 2018; 18(1):208.

32. Beaney T, Burrell LM, Castillo RR, Charchar FJ, Cro S, Damasceno A, et al. May measurement month 2018: a pragmatic global screening campaign to raise awareness of blood pressure by the International Society of Hypertension. Eur Heart J. 2019;40(25):2006-17.

33. Baimakangzhuo, Chunhua, Yangla, et al. Alcohol drinking behavior among native adult Tibetans in Lhasa. Chin J Public Health. 2015;32(5):609-12.

34. Cochrane J, Chen H, Conigrave KM, Hao W. Alcohol use in China. Alcohol Alcohol. 2003;38(6):537-42

35. Rehm J, Anderson P, Prieto JAA, Armstrong I, Aubin HJ, Bachmann M, et al. Towards new recommendations to reduce the burden of alcohol-induced hypertension in the European Union. BMC Med. 2017;15(1):173.

36. Zhao Y, Yan H, Marshall RJ, Dang S, Yang R, Li Q. Trends in population blood pressure and prevalence, awareness, treatment, and control of hypertension among middle-aged and older adults in a rural area of Northwest China from 1982 to 2010. PLoS One. 2013;8(4):e61779.

37. Wilkins K, Campbell NR, Joffres MR, McAlister FA, Nichol M, Quach S, et al. Blood pressure in Canadian adults. Health Rep. 2010;21(1):37.

38. Evans DB, Hsu J, Boerma T, editors. Universal health coverage and universal access. Geneva: World Health Organization; 2013.

39. Zhang D-W, Yang J-W, Cui J-L, Li X, Li J, Lu P-J. Regional differences in prevalence, awareness, treatment, and control of hypertension among five provinces in southwest China. Chin J Public Health. 2019;35(10):1293-7.

40. Lu J, Lu Y, Wang X, Li X, Linderman GC, Wu C, et al. Prevalence, awareness, treatment, and control of hypertension in China: data from 1.7 million adults in a population-based screening study (China PEACE million persons project). Lancet. 2017;390(10112):2549-58.

41. Fryar CD, Ostchega Y, Hales CM, Zhang G, Kruszon-Moran D. Hypertension Prevalence and Control Among Adults: United States, 2015-2016. US Department of Health \& Human Services. 2017. DHHS Publication No. 2018 1209 CS283425.

42. Shafi ST, Shafi T. A survey of hypertension prevalence, awareness, treatment, and control in health screening camps of rural Central Punjab, Pakistan. J Epidemiol Glob Health. 2017;7(2):135-40.

43. Kayima J, Wanyenze RK, Katamba A, Leontsini E, Nuwaha F. Hypertension awareness, treatment and control in Africa: a systematic review. BMC Cardiovasc Disord. 2013;13:54.

44. Turnbull F, Woodward M, Neal B, Barzi F, Ninomiya T, Chalmers J, et al. Do men and women respond differently to blood pressure-lowering treatment? Results of prospectively designed overviews of randomized trials. Eur Heart J. 2008;29(21):2669-80.

45. Mufunda E, Albin B, Hjelm K. Differences in health and illness beliefs in zimbabwean men and women with diabetes. Open Nurs J. 2012;6:117-25.

46. Lewis CL, Chrastil HJ, Schorr-Ratzlaff W, Lam H, McCord M, Williams L, et al. Achieving 70\% hypertension control: how hard can it be? Jt Comm J Qual Patient Saf. 2020 Jun;46(6):335-41.

47. Aubrey-Bassler K, Fernandes C, Penney C, Cullen R, Meaney C, Sopcak N, et al. The effectiveness of a proven chronic disease prevention and screening intervention in diverse and remote primary care settings: an implementation study on the BETTER 2 Program. BJGP Open. 2019;3(3): bjgpopen19X101656.

\section{Publisher's Note}

Springer Nature remains neutral with regard to jurisdictional claims in published maps and institutional affiliations. 